\title{
Secreted Left Atrial P-Selectin in Mitral Stenosis after PBMV: When to Measure
}

\author{
M. Saifur Rohman
}

T

he glycoprotein P-selectin, a membrane component of cell storage granules, is rapidly translocated from $\alpha$-granules of platelets and the Weibel- Palade bodies of endothelial cells to the cell surface following an inflammatory process or other stimulations. P-selectin is a cell adhesion molecule of activated platelets and endothelial cells of interest because of its role in modulating interactions between blood cells and the endothelium, and also because of the possible use of its soluble form in plasma as a predictor of adverse cardiovascular events. ${ }^{1}$

In endothelial cells, within minutes of its stimulation in vitro by inflammatory mediators, such as histamine, thrombin, or phorbol esters, or hypoxia, Weibel-Palade bodies are mobilized and their von Willebrand factor are degranulated. At the same time, $\mathrm{P}$-selectin is also expressed at the surface as quick astwo minutes after stimulation. However, this expressionis short-lived, reaching its peak after only 10 minutes, declining back to baseline levels after 3 hours. Additional synthesis of P-selectin is brought about within 2 hours by cytokines, such as interleukin-1 (IL-1), tumor necrosis factor- $\alpha$ (TNF- $\alpha$ ), and by thrombin, lipopolysaccharide or oxygen radicals. Immunofluores-

\footnotetext{
Alamat Korespondensi

dr. MSaifurroman, SpJP, PhD. Departemen Kardiologi dan Kedokteran Vaskular FK Universitas Brawijaya/RS Saiful Anwar, Malang. E-mail: ippoenk@yahoo.com
}

cence and confocal laser cytometry are usually used to measure the translocation upon this activation. ${ }^{1}$

As P-selectin is originally defined on activated platelets and they are easier to obtain and study, there are considerably more data from platelet compared to endothelial ones. There are approximately 10.000 P-selectin molecules on the surface of an activated platelet, translating to a density of perhaps 350 sites/ $\mu \mathrm{m}^{2}$, a density that exceeds even those on athrombin or histamine-stimulated endothelial cell in vitroby an approximate factor of ten. ${ }^{1,2}$ In this case, flow cytometry of activated platelet and microparticles was used to measure P-selectin.

The development of monoclonal antibody-based assay procedure (enzyme-linked immunosorbent assay (ELISA)) has allowed the quantification of P-selectin in fluids. The first commonly-asked question is: what is exactly beingmeasured? This point has arisen from the discovery of messenger RNA/cDNA coding for different variants of P-selectin, some of which coded for a molecule lacking a transmembrane portion, implying direct 'secretion' from the cell. It soon follows that the increased presence of a truncated soluble $\mathrm{P}$-selectin isoform in plasma might reflectan increase in the activity of this form of message. Alternative mechanisms for the appearance of soluble P-selectin include simple shedding or active cleavage from cell surface, presumably by a non-specific enzyme or other mediator(s) that may arise from leukocytes, endothelium, or elsewhere. The second question often asked is: where does the P-selectin come from? 
As P-selectin is present within both endothelial cells and the platelets, there has been considerable debate whether or not raised plasma levels of P-selectin reflects endothelial dysfunction, platelet activation, or both. Overall, there are too few serious data to contradict the proposition that raised soluble P-selectin reflects platelet disturbance. Therefore, a soluble form of it, detectableby ELISA, may present in the blood mainly because of increased platelet activation. ${ }^{1,3}$ Since soluble $\mathrm{P}$-selectin is produced not only by endothelial cells but also, even mainly, by platelets, all factors affecting platelet activation should also be considered as major contributors, in spite of production of endothelial P-selectin related to hemodynamic changes or reduced shear stress after percutaneous transvenous Balloon Mitral Valvulotomy(PBMV).

As mentioned, when soluble P-selectin is measured, confounding factors affecting P-selectin level should also be considered, such as previous treatment using calcium channel inhibitor, statin, anticoagulant and/ or antiplatelet. Cessation of smoking is also known to reduce soluble P-selectin. ${ }^{1}$

In mitral stenosis (MS), although there is a significant increasein mitral valve area and significant decrease in mean left atrial and pulmonary arterial pressures immediately after PBMV, there were no significant immediate (10 minutes after PBMV) changes found in plasma atrial P-selectin. Therefore, persistent increase in plasma P-selectin levels after PBMV might be partly attributed to the persistent endothelial dysfunction after PBMV. Plasma soluble P-selectinlevels could not reflect changes in individual platelets, and there is an absenceof significant correlations between the plasma levels of soluble P-selectin in the left atrium and left atrial volume index, all of which reported by Shanti et al, who used 20 samples with wide variant of soluble P-selectin level from ELISA that resulted in big standard deviation. Similar results were also shown by Chen et al using the same sample size. However, previous studies with a larger sample size have shown significant decrease of left atrial Pselectin level at 24 hour, and 4 weeks after PBMV with no significant difference between peripheral and left atrial P-selectin. ${ }^{4,5}$ Hasan-Ali et al. showed that P-selectin change correlated with the change in left atrial diameter and pulmonary artery systolic pressure after 2 weeks of PBMV procedure in 65 patients. ${ }^{5}$ It may take a longer period of altered hemodynamic to reduce left atrial soluble P-selectin in MS patients following PBMV.

Taken together, many factors affected the change of left atrial soluble P-selectin level after PBMV, such as its baseline level, the effect of drugs affecting P-selectin expression and the duration of measurement from PBMV procedure.

\section{References}

1. Blann AD, Nadar SK, Lip GYH. The adhesion molecule Pselectin and cardiovascular disease. European Heart Journal. 2003;24: 2166-79.

2. McEver RP. Adhesive interactions of leukocytes, platelets, and thevessel wall during hemostasis and inflammation. ThrombHaemost2001;86:746-56.

3. Banu N, Avraham S, Avraham HK. P-selectin, and not Eselectin, negatively regulates murine megakaryocytopoiesis. J Immunol2002;169:4579-85.

4. Topaloglu S, Aras D, Ergun K, Geyik B, Ayaz S, Cay S, Cagirci G, Tufekcioglu O, Korkmaz S. Plasma level of soluble P-selectin in patients with rheumatic mitral stenosis and sinus rhythm undergoing percutaneous mitral balloon valvuloplasty. JThromb and Thrombolysis 2007; 23: 199-204.

5. Hasan-Ali H, Mosad E. Changes in platelet, coagulation, and fibrinolytic activities in mitral stenosis after percutaneous mitral valvotomy: role of hemodynamic change and systemic inflammation. ClinApplThrombHemost 2014 may 19 pii1076029614533144. [Epub ahead of print]. 